\title{
Un afán conservador, de Pablo Aravena (Ediciones Inubicalistas, Valparaíso, julio 2019)
}

\section{Sergio Rojas}

Filósofo, Profesor Titular de la Universidad de Chile.

Tengo con Pablo Aravena una larga relación de amistad e intercambio intelectual, compartiendo inquietudes, bibliografías, iniciativas académicas, el gusto por el rock, largas conversaciones de bar o restaurante después de un coloquio o de una mesa de trabajo en la universidad, en fin, como decía, una larga relación de amistad.

Reconozco en el libro que ahora comentamos los temas que han nutrido nuestra comunicación intelectual en estos años, varios de estos textos los conocía desde antes, algunas de las reseñas incluidas corresponden precisamente a publicaciones de mi autoría.

Uno de los motivos que cruza los escritos aquí reunidos expresa la necesidad de pensar a contrapelo de la burocratización del pensamiento que hoy se impone en el marco de un imperativo de "acreditación" generalizada, en la que cada académico debe manejar su carrera como si fuese una empresa personal. En este contexto, celebro la aparición de un libro como este, en el que la voluntad de pensar es a la vez voluntad de diálogo.

Dejarse interpelar por la experiencia de nuestro tiempo, intentar hacerse contemporáneo de lo que (nos) acontece, es exponerse. Me refiero a la necesidad de la reflexión, del diálogo, de la conversación, incluso de la discusión, cuando lo que nos convoca no es el claustro de emergencia citado por el director, la cuenta anual de una autoridad, el informe que la comisión deberá entregar en tres días más, etc., sino el hecho de que el paradigma epocal en el que habitamos se tambalea. Es lo que sucede cuando al leer la prensa me pregunto: ies que acaso "la realidad" definitivamente no funciona o se trata más bien de que así funciona?

Reconozco tres grandes discusiones en los escritos que componen este libro de Pablo: el presente de las humanidades, la realidad de la izquierda, el estatuto del tiempo presente.

\section{Las humanidades}

Respecto a la crisis de la figura del intelectual en nuestro tiempo, a la extinción de su lugar, escribe Aravena: "Si la desaparición de dichas condiciones 
elementales del discurso intelectual es preocupante en la vida pública, es francamente dramática en el espacio universitario, institución que -más allá de su total privatización y gestión como mera empresa- sufre directamente el impacto de la desaparición de sujetos letrados por efecto añadido de la extinción del mundo que los producía". En efecto, ¿cuál es hoy el lugar de las humanidades? ¿La nominación institucional de una Facultad? ¿Un principio administrativo del saber almacenado? ¿Un sector en la biblioteca? La cuestión de "los clásicos" y el canon.

La crítica de Aravena respecto a la existencia académica es lúcida e irónica. Como si en el presente lo que se denomina vida académica consistiera finalmente en acomodarse en una realidad en la que no ha quedado lugar para el pensamiento. Para muchos se trataría de sobrellevar esa falta de lugar, de sobreponerse al presentimiento de irrealidad que abruma cuando se reconocen reflexionar y generar conocimiento en un medio que dejó de leer: "Llevado al espacio universitario uno puede ver cómo se van dando distintas 'especies' de académicos: están los cándidos (...), los cínicos y finalmente los elitistas”. Los primeros, según Aravena, ignoran los signos de su intrascendencia confiando en el lugar que la institución les reconoce; los segundos exhiben su resignado escepticismo como una lucidez que se solaza en su propia impotencia; los terceros consideran que sus competencias e inteligencia excede toda posibilidad de reconocimiento y proceden estableciendo expectativas "privadas" con aquella minoría que, participando también de una cierta excelencia, puede valorarlos.

De lo anterior se sigue la importancia que Aravena reconoce en un tipo de escritura en la que toma cuerpo la reflexión cuando es convocada y exigida por concretas circunstancias. Señala -no exento de ironía- que "si las seguimos cultivando [columnas de periódico, reseñas de libros, intervenciones orales en eventos públicos] es porque constituyen la última expectativa de lectura pública -no intragremial- que tenemos: 'siendo breves y llanos quizá nos lean”. ¿Para qué se necesitan lectores?: "para construir una comunidad fundada en el uso público de la razón, en la crítica de la falsedad, la mentira, el oscurantismo, en fin, una comunidad vigilante de su libertad". Aravena es claro en subrayar el ejercicio público de la razón, algo que en la actualidad parece ir "a la baja". Sartre comenta que, en medio de los hechos de mayo del 68, minutos antes de hablar ante un auditorio multitudinario, recibe por mano un pequeño papel con el siguiente mensaje: "Sartre, sea breve por favor". El lugar del intelectual había comenzado a extinguirse.

Me interesa la idea de comunidad que sugiere Pablo. Byung-Chul Han, un autor cuya lectura compartimos, nombra a la sociedad de las redes digitales como la sociedad de "la indignación", la sociedad del escándalo. La indignación que se expresa en las redes es, por lo general, expresión individual: "Los individuos que se unen en un enjambre digital no desarrollan ningún nosotros". Su sentido último no es democrático, pues el "contenido" exhibe su derecho a ignorar el parecer y sentir 
de los demás; ocurre como si la verdad de su contenido consistiera precisamente en ostentar su indiferencia por los demás. En cambio, el espacio público que Pablo imagina desde su escritura se encuentra tramado dialógicamente.

\section{La izquierda}

El tratamiento de la izquierda en algunos de los escritos en este volumen se relaciona internamente con la preocupación de Pablo por la cuestión del tiempo histórico y el sostenido e importante trabajo que ha venido desarrollando en el campo de la teoría de la historia. Una de las cuestiones centrales aquí es la pregunta por la necesidad y posibilidad de un sujeto histórico.

La izquierda no sólo tiene un pasado, sino que pareciera que sólo tiene pasado. ¿Dónde existe la izquierda hoy? En la universidad, sin duda, y ¿más allá de esta? Existe injusticia, desigualdad, malestar, dolor, por cierto, pero ¿qué hace hoy $a$ la izquierda en medio de todo esto? En algunos de estos escritos la crítica a la izquierda expresa su reflexivo compromiso con esta, al punto de que por momentos pareciera que decir de alguien que es historiador y agregar que se trata de un historiador "de izquierda" viene a ser una especie de pleonasmo.

Es claro que para Pablo ser de izquierda hoy no es una posición ni una dirección ya nítidamente trazada (como cuando decimos "tomar la izquierda"), sino un trabajo que comienza por poner en cuestión los lugares comunes que hacen a priori de la izquierda una posición. Uno de esos a priori consiste en una cierta representación de lo que puede ser "el pueblo": "El heroísmo nunca alcanzó para desplazar esta miseria humana. La miseria de un populacho que, a cambio de pan y circo, y resignado en su servilismo, estaba dispuesto a asentir las más atroces aberraciones del poderoso. Es por esto que, desde muy temprano, tuve problemas por comprender a qué 'pueblo' se refería Allende en sus discursos, cuál era ese sujeto colectivo que tendría que retornar libre por las anchas alamedas". No se trata en lo esencial de un cuestionamiento teórico al ejercicio discursivo de la política en aquellos años de convulsa cotidianeidad, sino de una crítica a la izquierda que hoy tiene la mirada dirigida hacia el pasado, como buscando una épica que pueda ser útil en el presente.

Una curiosa forma de dar lugar a la utopía en el presente, cuando el sentido de esta ya no estaría en el futuro, sino en el pasado de una izquierda que parece decir "creímos una vez en un futuro". "Una actitud que busca recomponer el orden pre-UP, ya que, si bien aquella sociedad tenía sus vicios, poseía un atributo que el candor de las pasiones utópicas no les había dejado ver en ese entonces: un consenso político que hacía posible la democracia, roto ese consenso vino la catástrofe. El presente y el futuro de Chile debían parecerse al pasado". La propuesta de Aravena es clara: es necesario que la izquierda levante la vista desde el pasado: 
"es justamente esta aparente evidencia rotunda, esta especie de consenso de izquierda sobre la UP como utopía del pasado, lo que nos debe alarmar". Esto implica, a la vez, descargar al pasado de las expectativas de un presente políticamente debilitado. Es decir, es necesario volver sobre el período de la UP y reflexionar críticamente lo que fue ese proceso. Lo que Aravena lúcidamente sugiere es que la UP se transformó en un proyecto utópico a posteriori: como utopía "la UP sólo puede ser una utopía del pasado, lo que tiene que ver no únicamente (...) con el sentido de las muertes y víctimas, sino (...) con la 'no disponibilidad' hoy del futuro. En su propio momento ¿era tan evidente como hoy que la UP era un proyecto utópico?". Pareciera que miramos hacia atrás buscando un futuro, buscando un tiempo que tenía el futuro por delante.

\section{El estatuto del tiempo presente}

Reconocemos que no comprendemos lo que hacemos, que hay un sentido pendiente en el presente y que esto tiene que ver con un pasado que torna extraña la cotidianeidad en la que arraigamos. François Hartog -autor de importante referencia en el pensamiento de Aravena- denomina presentismo al hecho de que hoy la realidad de los acontecimientos mismos se impone sobre cualquier forma de sentido interpretativo. Esto no implica la simple captura de la subjetividad en el vértigo de la "actualidad" (lo contingente, lo efímero, lo irrelevante, etc.), sino el estallido de la realidad misma, diseminada en una pluralidad de acontecimientos después del agotamiento de las narraciones que permitían elaborar procesos de sentido en curso, causalidades, períodos. Es todo lo contrario a un simple desentenderse del pasado, porque ahora el devenir se despliega en un horizonte colmado de acontecimientos que no parecen tener más sentido que aquel que desde el presente sea posible reconocer o atribuirles.

El presente se siente responsable de un pasado que no comprende, y es precisamente esto lo que le encarga hacer presente ese pasado. Según Hartog: "nuestras experiencias cotidianas son las de un mundo que privilegia lo directo y lo interactivo, el tiempo real (...), que habla más fácilmente de 'pasado' (categoría imprecisa) que de historia, que le da mucha importancia a la conmemoración, a la puesta en escena y a todas las técnicas de presentificación más que a la explicación”. Esto incide directamente en la categoría de lo contemporáneo, por cuanto ésta ya no constituye propiamente un período, sino que señala más bien un tiempo que emerge con la supresión de la frontera entre presente y pasado, cuando este parece inundar el presente no dejando lugar al futuro. Escribe Aravena: "ya no disponemos de la idea de futuro. 0 al menos este ya no es lo que era un campo en donde se podía extender la racionalidad para realizar lo que aún faltaba para la realización plena de nuestra humanidad". Una especie de "memorialismo" se hace dominante en el 
presente, confrontándose con la actualidad del "día a día", como si desde ese pasado irresuelto se ejerciera una fuerza de gravedad a la que es necesario atender; como si, paradójicamente, lo tremendo que yace contenido en ese pasado que no se marcha fuese un antídoto contra la vacuidad y el sin sentido de lo meramente "actual".

Paradójica nostalgia del futuro contenida en el atesoramiento del supuesto coeficiente utópico del pasado: "[la relación nostálgica con la utopía] es la relación de unas generaciones 'de transición' que (...) aún porta energías utópicas o expectativas futuristas en un tiempo en que el futuro se nos ha clausurado. Es probable que al cabo de un par de generaciones más ya nadie extrañe el futuro". Varios de los escritos en este libro aplican este problema a la ciudad de Valparaíso: "El presente patrimonial de Valparaíso impone el consumo del pasado antes que su conocimiento".

La propuesta "conservadora" de Pablo en este libro, desde su título, es todo lo contrario a resistir en lo consabido, aferrarse a la tierra firme de los prejuicios compartidos, sino que se trata de insistir en el trabajo del pensamiento que se orienta hacia lo inédito como la vocación que le es más propia. "mientras no estemos (...) dispuestos a pensar lo inédito en la historia, nuestros discursos seguirán siendo impotentes o derechamente conservadores".

La escritura en este volumen trasunta el clima de diálogo y también de discusión en el que han tenido origen los artículos, columnas de periódicos y reseñas que lo componen. ¿Y lo "conservador" de su afán? Bueno, es todo lo conservador que nos puede parecer la escena de un grupo de personas que, en medio de esa agitada facticidad en la que toma cuerpo lo inédito, dialogan acerca del extraño tiempo que les ha tocado vivir. 